\title{
Magnitude and associated factors of undernutrition (underweight and stunting) among school adolescent girls in Hawzen Woreda (District), Tigray regional state, Northern Ethiopia: Cross-sectional study
}

\author{
Kidanemaryam Berhe ${ }^{1 *}(\mathbb{D}$ and Gebrehiwot Gebremariam²
}

\begin{abstract}
Objective: There is a lack of evidence concerning undernutrition (underweight and stunting) among adolescent girls in the study area, therefore, this study aimed to assess the magnitude of undernutrition and associated factors among adolescent girls in Hawzen woreda, Northern Ethiopia.

Results: This study found that $32.2 \%$ and $33.2 \%$ of school adolescent girls were underweight and stunted respectively. Illiterate fathers were higher among underweight adolescent girls as compared to those normal-weight adolescent girls ( $\mathrm{AOR}=1.4,95 \% \mathrm{Cl} ; 1.1,1.7)$. Underweight adolescents were higher among low-grade level adolescents (grade 4-8) as compared to grade $9-12$ adolescents ( $\mathrm{AOR}=2,95 \% \mathrm{Cl} ; 1.4,2.6)$. Unemployed mothers were higher among stunted adolescent girls as compared to the counterpart ( $\mathrm{AOR}=2.2,95 \% \mathrm{Cl} ; 1.1,3.3$ ). It would be good to consider the above-mentioned factors during the nutritional intervention of adolescents.
\end{abstract}

Keywords: Underweight, Stunting, Adolescent girls, Hawzen

\section{Introduction}

World Health Organization (WHO) defined adolescents as persons aged 10-19 years [1]. Adolescents gain fifty percent of adult weight and more than twenty percent of their adult height during this period. The adolescents are generally expected to enjoy good health and being less vulnerable to infection compared with under-five children and of chronic diseases compared with aging people, and hence they have generally being given little health and nutritional attention except for reproductive health concern. Undernutrition is a major public health

\footnotetext{
*Correspondence: kidane0920@gmail.com

${ }^{1}$ Department of Nutrition and Dietetics, School of Public Health, College

of Health Sciences, Mekelle University, Tigray, Ethiopia

Full list of author information is available at the end of the article
}

problem among adolescent girls all over the world. In developing countries including Ethiopia, half of all adolescents fail to achieve their full genetic growth potential. Poor dietary diversity, poor dietary inadequacies, frequent illness, lack of health care access, increased nutritional requirement can affect adolescent nutrition [2-4]. Undernourished adolescents have lowered resistance to infection; they are more likely vulnerable to common diseases like diarrheal diseases and respiratory infections [5-8]. Adolescent's undernutrition in Asia and Africa is generally higher with a magnitude of $32-65 \%$ and $4-30 \%$ respectively. In Sub Sahara Africa, the magnitude of adolescence under-nutrition is $15-58 \%$, which is higher from other African countries $[6,9,10]$. There is a lack of evidence concerning adolescent girls' undernutrition in the study area. Therefore, this study aimed to assess 
the magnitude and associated factors of undernutrition (underweight and stunting) among adolescent girls in Hawzen woreda, Northern Ethiopia.

\section{Main text}

\section{Methods and materials}

The study was conducted in Hawzen woreda, Tigray, Northern Ethiopia at school level from December 2017 to January 2018. Hawzen woreda is located in the Eastern part of the Tigray regional state, at a distance of $950 \mathrm{~km}$ from Addis Ababa and $84 \mathrm{~km}$ from Mekelle town. According to the 2007 Central Statistics Agency of Ethiopia (CSA), the woreda has a total population of 117,954 . The woreda has 34 schools; 30 of them are primary (1-8 grade) and 4 are secondary (9-12 grade) schools. A total of 29,840 students (15,568 girls) attend their education in these schools.

The institution (school) based cross-sectional study design was applied and the study population was adolescent girl students attending their education in selected primary and secondary schools of Hawzen woreda. Adolescent girl students who were residents of the woreda for at least 6 months were included in the study but adolescent girl students who had physical deformity were excluded due to the difficulty for anthropometric measurements. The sample size was calculated using a single population proportion formula based on the prevalence rate of underweight which was $37.8 \%$ [11] and 95\% level of confidence and 5\% marginal error. By adding 10\% for non-respondent rate, the total sample size became 398 . Lottery method was used to select fifteen schools from a total of 34 schools then the total sample size was properly allocated for the selected schools according to the number of students they have. Classes (sections) and participants were selected by the lottery method. The dependent variable was undernutrition (underweight and stunting) and the independent variables were socio-demographic factors, diet, personal hygiene and sanitation, behavior and lifestyle and anthropometric measurements. Underweight is Body Mass Index (BMI) for age $<-2$ standard deviation (SD). Stunting is the height for age $<-2 \mathrm{SD}$. A pre-test was done on $5 \%$ of student adolescent girls at another woreda. Training was given for 2-days. Weighing scales were calibrated with known weight object regularly. On a daily basis, the collected information was reviewed manually. Questionnaires that had missing data were returned to the data collectors to fill the missed data by contacting the adolescent girl.

The data were analyzed using the statistical package for social sciences (SPSS) software version 20 for analysis. Descriptive statistics were done to show the magnitude of undernutrition (underweight and stunting) and participant characteristics. Associations between dependent and independent variables were checked using binary logistic regression analysis. Variables with $p$ value $<0.25$ in the bivariate analysis were transferred to multivariable logistic regression. In multivariable logistic regression, p-value $<0.05$ was used to declare statistical significance. Adjusted odds ratio with its $95 \%$ confidence intervals was also computed.

\section{Results \\ Socio-demographic and economic characteristics}

A total of 398 adolescent girls (10-19 years old) from fifteen schools were enrolled in this study which made the respondent rate $100 \%$. Majority of the study groups were in the age range of 14-19 years and almost all respondents were identified as orthodox Christian. More than two-thirds of the study participants live in rural areas. The literacy rate of fathers and mothers were found to be $72.4 \%$ (284) and $51.8 \%$ (206) respectively. About $64.6 \%$ of fathers and $69.8 \%$ of mothers were identified as farmers and housewife respectively (Table 1).

\section{Dietary factors}

About 94\% (374) of respondents usually ate three and more than three meals per day. Enjera with shirowet was stapled diets for $97.7 \%$ of respondents. Thirty-seven percent of the participants got their routine diet from their own product (Table 2 ).

\section{Lifestyle and behavioral factors}

About $75.9 \%$ (302) of respondent adolescent girls had work other than learning. About 62.6\% (249) of adolescent girls travel less than $40 \mathrm{~min}$ to reach the school. Ninety-five percent (378) and 77.6\% (309) of the study participants neither smoke cigarettes nor drink alcohol respectively (Table 2 ).

Table 1 Socio-demographic characteristics of adolescent girls in schools of Hawzen woreda, Northern Ethiopia, 2018

\begin{tabular}{lll}
\hline Variables & Frequency $(\mathbf{n})$ & Percentage (\%) \\
\hline Grade level & & \\
$4-8$ & 154 & 38.7 \\
$9-12$ & 244 & 61.3 \\
Income & & \\
$<300$ birr & 52 & 13.1 \\
$301-500$ & 61 & 15.3 \\
$501-1000$ & 113 & 28.4 \\
$>1000$ & 172 & 43.2 \\
Family size & & \\
$\leq 4$ & 177 & 44.5 \\
$>4$ & 221 & 55.5 \\
\hline
\end{tabular}


Table 2 Diet, lifestyle, behavioral and environmental factors among adolescent girls in schools of Hawzen woreda, Northern Ethiopia, 2018

\begin{tabular}{|c|c|c|}
\hline Variables & Frequency $(n)$ & Percentage (\%) \\
\hline \multicolumn{3}{|c|}{ Number of meals per day } \\
\hline Once & 2 & 0.5 \\
\hline Twice & 22 & 5.5 \\
\hline Three and above & 374 & 94 \\
\hline \multicolumn{3}{|l|}{ Source of diet } \\
\hline Own product & 148 & 37.2 \\
\hline From market & 220 & 55.3 \\
\hline From donors & 30 & 7.5 \\
\hline \multicolumn{3}{|c|}{ Do you work on top of learning } \\
\hline No & 96 & 24.1 \\
\hline Yes & 302 & 75.9 \\
\hline \multicolumn{3}{|c|}{ School distance for the home of the adolescent girl } \\
\hline$<40 \min$ & 249 & 62.6 \\
\hline $40-60 \mathrm{~min}$ & 100 & 25.1 \\
\hline$>60 \mathrm{~min}$ & 49 & 12.3 \\
\hline \multicolumn{3}{|c|}{ Do you smoke a cigarette } \\
\hline No & 378 & 95 \\
\hline Yes & 20 & 5 \\
\hline \multicolumn{3}{|c|}{ Source of drinking water } \\
\hline Tap water & 384 & 96.5 \\
\hline River water & 3 & 0.7 \\
\hline Protected well & 7 & 1.8 \\
\hline Unprotected well & 4 & 1 \\
\hline \multicolumn{3}{|c|}{ The distance of the source of water for drinking } \\
\hline$<5 \min$ & 310 & 77.8 \\
\hline $5-15 \min$ & 47 & 11.8 \\
\hline $16-30 \mathrm{~min}$ & 23 & 5.7 \\
\hline$>30 \min$ & 19 & 4.7 \\
\hline
\end{tabular}

\section{Environmental factors}

From a total of 398 respondents, about 96.5\% (384) use drinking water from the improved source (pipe water). Three hundred sixty-nine participants had latrine of which $39.2 \%$ (156) of the latrine was pit latrine (Table 2).

\section{The magnitude and associated factors of undernutrition among adolescent girls}

About 32.2\% (128) of the adolescent girls were underweight and 33.2\% (133) adolescent girls were stunted. About 8.8\% (35) of adolescent girls had both underweight and stunting. In the bivariate logistic regression; residence, age, father occupation, mother occupation, father education, grade level, income, meal frequency, latrine, and illness had a p-value of $<0.25$ and these variables were taken to the multivariable logistic regression model. In the multivariable logistic regression; illiterate father and low-grade level were significant factors for underweight and unemployed mother was the only significant factor for stunting. Illiterate fathers were higher among underweight adolescents compared to that normal weight (AOR $=1.4,95 \% \mathrm{CI} ; 1.1,1.7)$. Underweight adolescents were higher among low-grade level adolescents (grade 4-8) as compared to high-grade level adolescents (9-12) (AOR $=2$, 95\% CI; 1.4, 2.6). Unemployed mothers were higher among stunted adolescents as compared to the counterpart $(\mathrm{AOR}=2.2,95 \% \mathrm{CI} ; 1.1,3.3)$ (Table 3).

\section{Discussion}

This study showed that $32.2 \%$ of school adolescent girls were underweight. This magnitude is higher as compared to other studies conducted in Arsi Zone (14.5\%), Ambo (27.2\%), Adama city (21.3\%), Bale Zone (13.7\%), Arbaminch (19.7\%), West Harage (24.24\%), Northern Ethiopia (26.1\%), Adwa town (21.4\%), Addis Ababa (6.2\%), Ethiopia (13.6\%), Zambia (13.7\%), Nigeria (18.6\%), seven Africa countries (12.6\%-31.9\%), Latin America and Caribbean countries $(3 \%-22 \%)$ [8, 12-24]. This might be due to the low socioeconomic status in this study area. The magnitude of underweight in this study is low as compared to the magnitude reported from studies conducted in Mekelle city (37.8\%), Eastern Tigray (55\%), Tigray (58.3\%), Bangladesh (67\%), and India (49\%) [25-29]. This could be due to the time gap variation in which currently improved awareness about nutrition in adolescent parents and the current nutritional intervention. The magnitude of underweight in this study is consistent with the magnitude of underweight in Myanmar [28].

The magnitude of stunting in this study was $33.2 \%$. This is higher than the study result from Arsi Zone (20.2\%), Adama city (15.6\%), West Hararge (7.2\%), North Ethiopia (28.5\%), Adwa town (12.2\%), Eastern Tigray (25.5\%), Tigray Region (26.5\%), Addis Ababa (7.2\%), Ethiopia (31.5\%), Indonesia (23.6\%) [12, 14, $17-20,26,27,30]$. The difference could be due to differences in socio-demographic and economic status. The magnitude of stunting in this study is lower as compared studies conducted in South East Asian countries; Bangladesh (48\%), Myanmar (39\%) and India (54\%) $[28,29]$. This difference may be due to the difference in cultural and dietary practices. The magnitude of stunting in this study is within the range of the magnitude reported from Latin America and Caribbean countries (7-43\%) [24].

In this study, the father's educational status was associated with adolescent girls underweight. This finding is in line with findings of studies conducted in Adama city, West Hararge and Ethiopia [14, 20, 27]. Higher educational status of a father can relate with a good income, good knowledge, availability and access to a balanced 
Table 3 Bivariate and multivariable logistic regression analysis for undernutrition among adolescent girls in Hawzen woreda, Northern Ethiopia, 2018

\begin{tabular}{|c|c|c|c|c|c|c|c|c|}
\hline \multirow[t]{2}{*}{ Variables } & \multicolumn{2}{|c|}{ Underweight } & \multirow[t]{2}{*}{ COR $(95 \% \mathrm{Cl})$} & \multirow[t]{2}{*}{ AOR $(95 \% \mathrm{Cl})$} & \multicolumn{2}{|c|}{ Stunting } & \multirow[t]{2}{*}{$\operatorname{COR}(95 \% \mathrm{Cl})$} & \multirow[t]{2}{*}{ AOR $(95 \% \mathrm{Cl})$} \\
\hline & Yes & No & & & Yes & No & & \\
\hline \multicolumn{9}{|l|}{ Residence } \\
\hline Urban & 39 & 114 & 1 & 1 & 45 & 108 & 1 & 1 \\
\hline Rural & 89 & 156 & $1.7(1.1,2.3)$ & $1.2(0.3,3.1)$ & 88 & 157 & $1.5(1.01,1.9)$ & $1.4(0.5,2.3)$ \\
\hline \multicolumn{9}{|l|}{ Age } \\
\hline $10-13$ & 30 & 36 & $1.9(1.2,2.6)$ & $0.6(0.2,1)$ & 32 & 34 & $1.6(1.2,2)$ & $0.8(0.1,1.5)$ \\
\hline $14-19$ & 98 & 234 & 1 & 1 & 101 & 231 & 1 & 1 \\
\hline \multicolumn{9}{|l|}{ Father occupation } \\
\hline Unemployed & 124 & 235 & $4.6(1.6,7.6)$ & $8.1(0.5-123.5)$ & 122 & 237 & $1.3(0.6,2)$ & $3.19(1.93-6.4)$ \\
\hline Employed & 4 & 35 & 1 & 1 & 11 & 28 & 1 & 1 \\
\hline \multicolumn{9}{|c|}{ Mother occupation } \\
\hline Unemployed & 114 & 204 & $2.6(1.02,4.2)$ & $2.4(1.2,3.6)$ & 123 & 200 & $3.9(1.5,6.3)$ & $2.2(1.1,3.3)^{*}$ \\
\hline Employed & 14 & 66 & 1 & 1 & 10 & 65 & 1 & 1 \\
\hline \multicolumn{9}{|l|}{ Father education } \\
\hline Illiterate & 44 & 70 & $1.5(1.02,1.9)$ & $1.4(1.1,1.7)^{*}$ & 92 & 73 & $5.6(0.7,10.5)$ & $1.6(1.01,2.2)$ \\
\hline Literate & 84 & 200 & 1 & 1 & 41 & 192 & 1 & 1 \\
\hline \multicolumn{9}{|l|}{ Grade level } \\
\hline $4-8$ & 66 & 88 & $2.2(1.4,3)$ & $2(1.4,2.6)^{*}$ & 64 & 90 & $1.8(1.2,2.4)$ & $1.5(1.01,1.9)$ \\
\hline $9-12$ & 62 & 147 & 1 & 1 & 69 & 175 & 1 & 1 \\
\hline \multicolumn{9}{|l|}{ Income } \\
\hline$<500$ birr & 13 & 39 & $0.9(0.4,1.4)$ & $0.4(0.1,0.7)$ & 13 & 39 & $0.7(0.3,1.1)$ & $0.5(0.1,0.9)$ \\
\hline 500-1000 birr & 23 & 38 & $1.6(0.9,2.3)$ & $0.9(0.3,1.5)$ & 20 & 41 & $0.9(0.5,1.3)$ & $0.4(0.02,0.78)$ \\
\hline 1000-1500 birr & 45 & 68 & $1.8(1.1,2.5)$ & $1.2(0.5,1.9)$ & 42 & 71 & $1.2(0.7,1.7)$ & $0.8(0.3,1.3)$ \\
\hline$>1500$ birr & 47 & 125 & 1 & 1 & 58 & 114 & 1 & 1 \\
\hline \multicolumn{9}{|c|}{ Frequency of meal per day } \\
\hline $1-2$ meals & 12 & 12 & $2.2(1.03,3.4)$ & $1.06(0.08-3.4)$ & 9 & 15 & $1.2(0.5,1.9)$ & $0.2(0.009-4.46)$ \\
\hline$\geq 3$ meals & 116 & 258 & 1 & 1 & 124 & 250 & 1 & 1 \\
\hline \multicolumn{9}{|l|}{ Latrine availability } \\
\hline Yes & 115 & 254 & 1 & 1 & 118 & 251 & 1 & 1 \\
\hline No & 13 & 16 & $0.6(0.3,0.9)$ & $2.7(0.2,5.2)$ & 15 & 14 & $0.4(0.2,0.6)$ & $2.2(0.6,3.8)$ \\
\hline \multicolumn{9}{|l|}{ Illness in 2 weeks } \\
\hline Yes & 31 & 52 & $1.3(0.8,1.8)$ & $2.8(1.05-4.02)$ & 26 & 57 & $0.8(0.5,1.1)$ & $2.72(0.04-4.76)$ \\
\hline No & 97 & 218 & 1 & 1 & 107 & 208 & 1 & 1 \\
\hline
\end{tabular}

$1=$ reference category, ${ }^{*}=p$-value $<0.05$

diet. Adolescent girls from grades four to eight were more likely to be underweight as compared to grade 9-12 adolescent girls. This finding is consistent with study findings conducted in Jimma zone and Zambia [21,31]. Adolescent girls who attain higher grade level (9-12) can get awareness about nutrition from previous nutrition education interventions, from biology and chemistry [21]. This study showed that unemployed mothers were 2.2 times higher in stunted adolescent girls as compared their counter parts. This finding is in line with a study finding done in India [8]. This can be due to the low income, and food of unemployed mothers. The findings of this study showed that adolescent undernutrition is a public health concern which needs development and strengthening of nutrition interventions.

\section{Limitation}

There was a possibility of recall bias and social desirability bias. Due to the nature of the study design, it was difficult to establish a cause-effect relationship.

\section{Abbreviations}

AOR: Adjusted odds ratio; BMI: Body Mass Index; Cl: Confidence interval; CSA: Central Statistics Agency; SD: Standard deviation; SPSS: Statistical package for social science; WHO: World Health Organization. 


\section{Acknowledgements}

We would like to thank Tigray regional health bureau, Eastern Zone of Tigray and schools for their support and cooperation. Our special thanks go to study participants, data collectors and supervisors for their full cooperation during the research activities.

\section{Authors' contributions}

Conceptualization: KB. Data collection: KB, GG. Formal analysis: KB, GG. Investigation: KB, GG. Methodology: KB, GG. Project administration: KB, GG. Software: KB, GG. Supervision: KB, GG. Validation: KB, GG. Visualization: KB, GG. Writing original draft: KB, GG. Writing review and editing: KB, GG. Both authors read and approved the final manuscript.

\section{Funding}

The funder was Adigrat University and the amount of the fund was 500 USA dollars. The funder didn't have a role in the study design of the study, collection, analysis, interpretation of data and in writing the manuscript.

\section{Availability of data and materials}

All data generated or analyzed during this study are included in this published article

\section{Ethics approval and consent to participant}

Ethical approval was found from the ethical committee called the College of Medicine and Health Sciences Research and Community Service Ethical Committee (CMHS-RCS-EC), Adigrat University. The committee's reference number for this research was AGU/CMHS/R/008/18. Written permission was obtained from the Tigray Regional Health Bureau, district/woreda education offices and selected schools. Further, study participants were briefed about the main objective of the study. Participants were informed that they have the full right to refuse to participate in the study or can interrupt/withdraw if they want. Confidentiality of the information was assured and the privacy of the study participants was respected and kept as well. Written informed consent was obtained from each study participant and/or from parents/guardians of $<16$ years old adolescent girls. At the last adolescent girls were counseled on personal hygiene, sanitation, nutritional practices, and a healthy lifestyle.

\section{Consent for publication}

Not applicable.

\section{Competing interests}

The authors declare that they have no competing interests.

\section{Author details}

${ }^{1}$ Department of Nutrition and Dietetics, School of Public Health, College of Health Sciences, Mekelle University, Tigray, Ethiopia. ${ }^{2}$ Public Health Department, College of Health Sciences, Adigrat University, Tigray, Ethiopia.

Received: 7 August 2019 Accepted: 28 January 2020

Published online: 07 February 2020

\section{References}

1. World Health Organization. Nutrition in adolescence-issues and challenges for the health sector, "Issues in Adolescent Health and Development. Geneva: Switzerland; 2005.

2. Stang J, Story MT. Guidelines for adolescent nutrition services. 2005; Chapter 1, pp. 1-8. ISBN 9241593660.

3. Lifshitz F, Tarim O, Smith MM. Nutrition in adolescence. Endocrinol Metab Clin North Am. 1993;22(3):673-83.

4. WHO. Reducing risks, promoting healthy life. The World health report. Geneva: Switzerland; 2002.

5. Story M. Alton nutrition issue and adolescent pregnancy. J Nutr Food Sci. 2005;30:142-3.

6. Cordeiro LS, Wilde PE, Semu H, Levinson FJ. Household food security is inversely associated with undernutrition among adolescents in Kilosa, Tanzania. J Nutr. 2012;142(9):1741-7.

7. Olaf M, Michael K. Malnutrition and health in developing countries. Can Med Assoc J. 2005:173(3):279-2786.
8. Tsgehana G, Takele T, Azeb A. Prevalence of Thinness and stunting and associated factors among adolescent school girls in Adwa Town, North Ethiopia. Int J Food Sci. 2016:2016:1-8.

9. Rosen JE. Adolescent health and development: A Resource Guide for World Bank Operations Staff and Government Counterparts. International Bank for Reconstruction and Development Washington DC.2004.

10. Charles D, Hélène F, Olivier R. Poor nutritional status of schoolchildren in urban and peri-urban areas of Ouagadougou, Burkina Faso. Nutr J. 2011;10(34):1-8.

11. Elena R, Lumina C. adolescent malnutrition from anthropological perspective Bucharest, Romania. Proc Rom Acad Series. 2007;2:155-8.

12. Yayehyirad $Y$, Abel G, Wondessen N, Dejene H, Taddesse A, Frehiwot M, et al. Undernutrition and its associated factors among adolescent girls in the rural community of Asako district, Eastern Arsi Zone, Oromia region, Eastern Ethiopia. Int J Clin Obstetr Gynecol. 2017;1(2):17-26.

13. Mesert $Y$, Jemal H, Hailu K, Fleming F. Socioeconomic and demographic factors affecting body mass index of adolescents students aged 10-19 in Ambo (a Rural Town) in Ethiopia. Int J Biomed Sci. 2010;6(4):321-6.

14. Roba KT, Abdo M, Wakayo T. Nutritional status and it's associated factors among school adolescent girls in Adama City, Central Ethiopia. J Nutr Food Sci. 2016;6(3):1-7. https://doi.org/10.4172/2155-9600.1000493.

15. Ahmed $Y$, Tomas B. Nutritional status and associated risk factors among adolescents girls in Agarfa High School, Bale Zone, Oromia Region, South East Ethiopia. Int J Nutr Food Sci. 2015;4(4):445. https://doi.org/10.11648 /j.ijnfs.20150404.15.

16. Dessalegn A, Jemal H, Gebrekirstos $G$, Desta H. assessment of the magnitude of the double burden of malnutrition and its associated factors among selected in-school adolescents in Arbaminch town, Southern Ethiopia. Int J Nutr Metab. 2017;9(4):30-7.

17. Damie TD, Wondafrash M, Teklehaymanot A. Nutritional status and associated factors among school adolescents in Chıro Town, West Hararge, Ethiopia. Gaziantep Med J. 2015;21(1):32-42.

18. Yohannes A, Gordon A, Tiffany K, Robert J, Zumin S. Prevalence and factors associated with stunting and thinness among adolescent students in Northern Ethiopia: a comparison to World Health Organization standards. Arch Public Health. 2015;73:44. https://doi.org/10.1186/s1369 0-015-0093-9.

19. Yoseph G, Solomon S, Balem D, Gessessew B. Nutritional Status of Adolescents in Selected Government and Private Secondary Schools of Addis Ababa, Ethiopia. Int J Nutr Food Sci. 2014;3(6):504-14. https://doi. org/10.11648/j.ijnfs.20140306.13.

20. Molla M, Azeb A, Melkie E, Getu D, Adamu B, Tibebu M. Predictors of nutritional status of Ethiopian adolescent girls: a community-based cross-sectional study. BMC Nutr. 2015. https://doi.org/10.1186/s4079 5-015-0015-9.

21. Bupe B. Nutritional status among female adolescents aged (15-19 years) in Zambia: why it matters. Horizon J Med Med Sci. 2015;1(1):001-7.

22. Chukwuma B, Anthony C, Kenechi A, Kevin C, Chinomnso C, Irene A, et al. Prevalence and determinants of adolescent malnutrition in Owerri, Imo State, Nigeria. Int J Sci Healthc Res. 2016;1(3):53-63.

23. Taru M, Hesham E, David T, Jason R. The prevalence of underweight, overweight, obesity and associated risk factors among school-going adolescents in seven African countries. BMC Public Health. 2014;14:887. https://doi.org/10.1186/1471-2458-14-887.

24. Pan American Health Organization. Underweight, short stature and overweight in adolescents and young women in Latin America and the Caribbean. 2008

25. Hadush G, Omer S, Huruy A. Assessment of nutritional status and associated factors among school going adolescents of Mekelle City, Northern Ethiopia. Int J Nutr Food Sci. 2015;4(1):118-24. https://doi.org/10.11648 /j.ijnfs.20150401.26

26. Weres Z, Yebyo H, Miruts K, Gesesew H, Woldehymanot T. Assessment of adolescents' under nutrition level among school students in Eastern Tigray, Ethiopia: a cross-sectional study. J Nutr Food Sci. 2015;5:402. https ://doi.org/10.4172/2155-9600.1000402.

27. Afework M, Fitsum H, Barbara S, Gideon K, Vincent L, Zenebe A, et al. Nutritional status of adolescent girls from rural communities of Tigray, Northern Ethiopi. Ethiop J Health Dev. 2009;23(1):6-11.

28. World Health Organization. Adolescent nutrition: a review of the situation in selected South-East Asian Countries. Geneva: WHO; 2006. 
29. Amitava P, Amal K, Arunangshu S, Prakash C. Prevalence of undernutrition and associated factors: a cross-sectional study among rural adolescents in West Bengal, India. Int J Pediatr Adolesc Med. 2017;4:9e18.

30. Sitti P, Andi I, Ida R, Abdul R. Low socioeconomic status among adolescent schoolgirls with stunting in Maros district, South Sulawesi in Indonesia. Int Proc Chem Biol Environ Eng. 2016;95:75-9.

31. Huruy A, Tefera B, Legesse N. Socioeconomic factors associated with underweight and stunting among adolescents of Jimma Zone, South
West Ethiopia: a cross-sectional study. London: Hindawi Publishing Corporation; 2013.

\section{Publisher's Note}

Springer Nature remains neutral with regard to jurisdictional claims in published maps and institutional affiliations.
Ready to submit your research? Choose BMC and benefit from:

- fast, convenient online submission

- thorough peer review by experienced researchers in your field

- rapid publication on acceptance

- support for research data, including large and complex data types

- gold Open Access which fosters wider collaboration and increased citations

- maximum visibility for your research: over $100 \mathrm{M}$ website views per year

At BMC, research is always in progress.

Learn more biomedcentral.com/submissions 